\title{
Ten health stories that mattered this week: Mar. 2-6
}

- Health Canada plans to increase the frequency of planned and unplanned inspections of pharmaceutical manufacturing plants and will publish its findings online, reports the Toronto Star. An earlier Star investigation based on records from the US Food and Drug Administration found evidence of problems such as altered or hidden test data and the distribution of defective products.

- Canada is sending a team of five French-speaking public health experts to Guinea to assist in efforts to contain Ebola. Members of the team have expertise in emergency management, epidemiology and border screening, and will remain in Guinea for up two months.

- Citing the value of academic freedom to challenge established conventions, the University of British Columbia defended controversial work by two of its researchers linking aluminum adjuvants in vaccines to autism, autoimmune diseases and neurological problems, reports the Globe and Mail. The World Health Organization has discredited two of the researchers' studies, stating there is no causal link between the aluminum in vaccines and autism, and other medical experts have characterized the findings as misleading and scientifically irresponsible.

- Ontario Health Minister Dr. Eric Hoskins stated that the province is committed to transparency and accountability in health care in response to recommendations to improve the Quality of Care Information Protection Act. The 12 recommendations include increasing openness with patients and the public, creating a publicly available database of all critical incidents investigated in Ontario hospitals and allowing patients and families to request independent investigations.

- The British Columbia Nurses' Union is calling for more protection from violence for nurses following an attack on a nurse at Abbotsford Regional Hospital and Cancer Centre. The nurse was assaulted by a patient receiving medical and mental health treatment and suffered trauma to her head and face, as well as an eye injury requiring surgery.

- The University of Toronto is investigating materials presented in an alternative medicine course to determine if they contain inaccurate, anti-vaccine information. The teacher of the course is a homeopath and is married to the dean of the university's Scarborough campus, where the class is held.

- Police and health officials in British Columbia have launched a campaign to warn occasional drug users of the dangers of fentanyl. The potent opioid is being mixed with street drugs, unbeknown to most occasional drug users who have no tolerance to fentanyl. These people, not regular drug users, are at highest risk of bad outcomes, including deaths from overdose.

- About a quarter of Toronto adolescents report risky drinking behaviours (binge-drinking, mixing alcohol with energy drinks) and using a drug other than alcohol in the previous year, according to Healthy Futures, a survey of more than 6000 students in grades $7-12$ conducted by Toronto Public Health. Other areas of concern include self-harm, bullying, lack of physical activity and poor eating habits.

- The BC Supreme Court trial between Dr. Brian Day and the government of British Columbia has been delayed again, this time by three months (to June 1) because there are still thousands of documents relevant to the case that the government has not yet disclosed. Day, former president of the CMA, is challenging the constitutionality of laws prohibiting private billing for publicly insured medical procedures.

- The popular soft drink Coca-Cola has contained more sugar in Canada than in the US for more than a century, but that is changing. Coca-Cola Canada is reducing sugar in its version of the drink by $7 \%$ and calories by $12.5 \%$. The amount of sugar (39 g, down from $42 \mathrm{~g}$ ) and the number of calories (140, down from 160) in a $355 \mathrm{ml}$ can will now be the same as in the US. Roger Collier, CMAJ

CMAJ 2015. DOI:10.1503/cmaj.109-5013 